\title{
New combinations
}

Arie Rip*

\author{
By looking at science as a search process, disciplinary \\ demarcations become secondary, and new \\ combinations-which occur all the time-can be better \\ recognized. The practices of natural science contain social \\ science components (to discipline the world) and humanities \\ components (telling of stories), and the quality of these \\ components can be enhanced. The search perspective \\ unifies science and scholarship; the important differences \\ are not between natural science, social science and \\ humanities, but between 'grammar', '(hi)story' and \\ 'nomology', three ideal-typical approaches in search \\ processes. Existing scientific/scholarly developments and \\ new combinations can be located on this map. An \\ integrated science policy should create a stimulating \\ environment for new combinations.
}

Scientific disciplines are important for the organization of the work involved in the continuing cultivation of science. (The term 'cultivation of science' has an old-fashioned ring to it, in this age of strategic research, but it captures an important feature of science at the individual, group and societal level.) The disciplinary organization, as we know it now, emerged during the 19th century, and the creation of disciplinary structures remains an important step in the institutionalization of new research areas. However, after a time, disciplines are less able to maintain their function as the carrier of novelty production. 'New combinations"- to use a phrase of economist Joseph Schumpeter in another context-are made in spite of, rather than thanks to, the disciplinary organization of science.

I do not want to get into the discussion of multidisciplinarity or interdisciplinarity here, because one quickly gets stuck in concerns about disciplinary boundaries hindering the proposed interaction and integration. While this is indeed a problem, say in universities and in research

* Centre for Studies of Science, Technology and Society, University of Twente, P.O. Box 217, 7500 AE Enschede, The Netherlands. institutions, it is much more interesting to look at the intellectual innovations (or cognitive, or scientific, or scholarly-i do not want to be bound by particular terminology here) that do occur. One should then ask how and why these can occur; clearly, the rigidity of disciplinary boundaries cannot be the whole story.

In this article, I want to introduce a perspective on the cultivation of science that emphasizes the heterogeneity of the practice of doing science, its openness toward new combinations, and the implicit and explicit links between science, social science and even humanities. (In some other languages, this last point is taken care of because there is only one term, like Wissenschaft in German, to cover the whole spectrum.) $\mathrm{My}$ starting point, in line with recent philosophy and sociology of science, is that the cultivation of science consists of, and builds on, search processes. Continuing from that statting point, one can see further aspects of science in a new light. The 'new combinations' of my title occur all the time, although not all of them survive and become research areas and, in the end, new disciplines.

We can also see other types of new combinations, for example the increasing role of implicit and explicit social science work in, or 


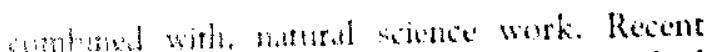

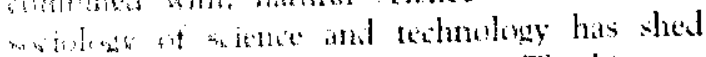
matreting lipht an whe practices. Thinking on

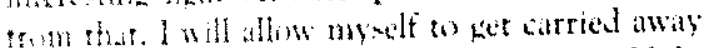

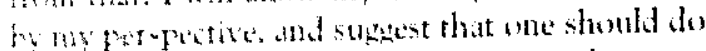

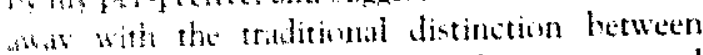
witenes, meial (and pehaviumal) science, and humantios. If hinders, rather than helps, the cultivation and progress of seience (in the sense of Wranshath, a human endeavour). The nature and arnitive dynamico of the intellectual, scholarly, sientifi: work ders not follow these institutional. iscidistimetions, and I will propose an alternative: the triande of nomology, grammar and history. The reater will have to suspend disbelief until the final part if this article, where I explain these unusual terms.

\section{Science as search processes}

Going into a modern laboratory and following what is happening there immediately convinces wit wif the heterogeneity of the work: physical instrumentation, chemical materials, hiological funtions, some micromengineering, some comfuting, some mathematics. Various skills have to he hruught to bear. It is in the work of writing up for a particular scientific or scholarly journal that a disciplinary slant is created. A piece of work can he written up in different ways, and be addressed to different specialities in a discipline, and sometimes to different disciplines.

Already in this simple example, one can see how science is a complex and heterogeneous activity, not to be captured by a few disciplinary labels. This holds even more strongly if one broadens one's scope and considers global distinctions as hetween natural and social sciences. However current and convenient these are (and I will use them for that reason), they cannot capture the peculiar nature of scientific and scholarly work. In line with recent philosophy of science, it is fruitful to focus on processes, rather than the structure of the resulting knowledge per se.

My starting point is to consider scientific research as a search process. Not just any search process, though. The needle lost in the haystack, and found after a diligent search--that does not count as science. Science is an open-ended search for something, but what it will be, one does not always know exactly.
Plato, in the Meno, argued that open-inded search is impossible, because one would not know whether one had actually found what one was louking for. Science has resolved this philosopher's ploy, by retrospectively re-defining whatever interesting thing that was found as the thing one night have been looking for. Columbus's voyage across the ocean, and his discovery of 'Cuba', is an interesting example: although, in a sense, he stumbled on America, he could tell a story about it that was interesting to geographers. In fact, his voyage was inspired, and his search guided, by heuristics derived from geographical knowledge (and practical experience) of the times. Similarly, the Madagascar fishermen drawing up Coelacanths in their nets were not the discoverers of the Coelacanths; whereas the biologist who recognized them for what they might be, was.

Scientific search processes also differ from the search of the detective, who wants to discover the presumably unique perpetrator of the crime-even if there is a lot of detective work involved in doing science, e.g. when the experiment does not work well and one has to find out what the cause (the criminal) is. It is different, not because science is not interested in the unique causes. Historians, but also geologists, and even cosmologists inquiring into Big Bangs, may inquire into unique causes. The point in science is that such causes, once found, make interesting stories to tell to others (not in the least colleague scientists and scholars) for their edification, and as an input into further search processes. In this way, one can identify the thin and sometimes blurred line that divides diagnostics, for example in medical practices, from medical research. (There have been proposals to be more liberal, and consider science on a continuum with detective work and psycho-analysis; the real interest of such proposals derives from the new aspects of search methods that become visible this way (repeated and cumulative diagnosis; semiotics) rather than the fact that one should broaden criteria for inclusion. ${ }^{1}$ )

To put it positively, the search processes aim at results that can be communicated to relevant audiences, and are structured in such a way as to convince these audiences of the value of the results (but this is not yet their 'truth': it takes some time before a scientific community accepts a finding as true). In order to be productive as well as convincing, the search follows certain rules, which 
one could call shared search heuristics. These range from using relevant instrumentation and data analysis, to shared intuitions about probable explanations. A paradigm, in the Kuhnian sense, can be usefully considered as a cluster of search heuristics (plus an exemplar). ${ }^{2}$ (In Kuhn's own work, ${ }^{3,4}$ as well as in the analysis of cognitive and technical norms and commitments in science, ${ }^{5}$ the shared chatacter of a paradigm of how search processes should be structured for the relevant group or research area, has been made very clear.)

The important point to be brought out from this altogether too brief consideration of scientific research is that search processes are localized, in a laboratory, an institute, in fieldwork; and that the generality of science is a result of the communication of outcomes of search to relevant audiences, and the 'organized scepticism' that is involved in the interaction at this more cosmopolitan level. The local work of scientific research is heterogeneous, and not necessarily limited to any one discipline. Porter and Rossini developed what they called the STRAP framework to describe what happened on the shop floor when actually doing science: Substantive knowledge, Technique, Range, Administrative unit complexity, Personnel, ${ }^{6}$ where the key point is that 'discipline' is replaced by 'intellectual skills', which are then split up in 'substantive knowledge' and 'technique'.' As I will argue below, one could, and should, extend their framework and show that the search processes on the shop floor contain even more components.

It is in the work of writing up for a particular scientific or scholarly journal that a disciplinary slant is created. As already noted, a piece of work can be written up in different ways, and be addressed to different specialities in a discipline, and sometimes to different disciplines.

So, disciplines are a matter of audiences, not a matter of ongoing scientific work. Still, they are important to the work, because the choice of heuristics and their value is derived from them. For this reason, the so-called Starnberg group of German scholars studying the development of science, emphasized the role of 'regulatives', which bridge the context of discovery and the context of justification. (Most of the work of this group was published in German; a brief overview in English is available. ${ }^{8}$ ) In an evolutionary approach to the philosophy of science, the outcomes of local search practices are delivered to the selection environment of the relevant scientific community. But it is Lamarckian evolution, not (neo-)Darwinian: the variations are not blind, but anticipate (through the heuristics, as well as the writing up) the evaluation, i.e. the eventual selection, by colleagues (who are also competitors).

A further advantage of this approach to science as search processes, and one which is important to my overall question, can now be brought out. The interactions with relevant audiences that i have sketched are not limited to whatever traditional disciplines have become institutionalized. New areas of research may emerge, which have to struggle to create a niche in the institutionalized landscape of science. Some are successful, others are not, or not yet. One need not limit oneself to the traditional bodies and practices of the scientific world.

Environmental sciences, for example, are organized differently, at least for some parts, with buteaus and consultancies playing a larger role, and with a stronger presence of decision-making audiences and their needs. Mission-oriented programmes in information technology and telecommunications, with the European programmes ESPRIT and RACE being well-known examples, have created a world peopled by scientists, engineers, industrialists and policy-makers, and it is in this world that the outcomes of scientific work are (also) evaluated.

Some commentators are concerned about such changes, which one could call 'epistemic' drift. ${ }^{9}$ But what is drifting away from the real goal, for some, is an interesting and challenging new venture for others. Changes should be welcomed, unless quality control is undermined-and criteria of quality control change as well; this is how science has evolved all along.

In fact, while one may not find a search for universal laws in these non-standard areas, there is still a definite move from local knowledge (or findings) to cosmopolitan knowledge. In that sense, the ideal of generalizability holds. But generalizability, as a methodological precept, should not be equated immediately with the logician's notion of induction, or some other feature of the logical structure of the knowledge. It is an action- or strategy-related concept: cosmopolitan knowledge can move about, can circulate, without losing its force. Such a way of looking at generalized or cosmopolitan knowledge is necessary to capture newly evolving research areas. 
While I have taken most of my examples from the natural sciences, I can apply my overall perspective and argument just as well to the social sciences and to history and most other parts of the humanities. Consequently, I have created a starting point from which to look at the processes of doing science and scholarly work with a fresh eye. Institutionally defined disciplinary demarcations become less important then. In addition, one can see through, or past them. One thing that one sees (and I draw on a large body of ethnographical studies of scientific practices here) is that in the practice of doing natural science, there are activities that relate to social and behavioural sciences.

\section{Doing natural science contains a social} science component

Search practices in natural science require, in order to be successful, some arranging and re-arranging of the material and the social world. Take, for example, the test plots in agricultural research, from the late 19th century onward, when the value of using artificial fertilizer was to be tested and/or demonstrated. The researcher had to find ways of making the test plots similar (often not knowing exactly what had to be checked for), and to keep them similar. Interference from natural forces had to be excluded, but also interference from humans. The farmers whose land was used had to be disciplined to take proper care; and those agricultural researchers who were better in disciplining the farmers could get better results.

The example of test plots can be followed over time, and one would see increasing sophistication in (re-)arranging the world, until present-day agriculture resembles the test-plots, writ large. The successes of agricultural science thus appear to depend more on the ability to change the world (which requires other competences than agricultural science provides) than on some presumed power of scientific knowledge per se. (This point refers back to my earlier discussion of cosmopolitan knowledge: circulation of the knowledge claims of agricultural science occurs in the group of comcolleagues-competitors/colleagues in agricultural science-not, or at least not as such, in the world of agriculture. Circulation in the latter world requires demonstration and adoption, and a willingness of farmers and other relevant actors to change their world and their behaviour. Understanding of such changes is a topic of social and behavioural science, not of agricultural science in the traditional sense.)

Some further recent developments fit very well in this perspective. In addition to actual test-plots, there are now also artificial test-plots, or testenvironments, and when used to check effects of genetically engineered micro-organisms or plants, they are called 'micro-cosms', which is an interesting analogy to 'laboratory'. ${ }^{10}$ There is also the new problem of disciplining (or better, pacifying) the action groups wanting to destroy test plots for generally modified organisms.

The example of test-plots, apart from its own interest, serves to make a general point: productive search requires 'restricted' conditions, where parameters can be controlled, instruments shielded from interference and passers-by fenced out. ${ }^{11}$ The laboratory is not just a building, it creates a protected space in the world. Researchers often take the existence of the laboratory and its infrastructure for granted; but it was carved out of the world, and has to be maintained. Outside electromagnetic fields have to be disciplined by having Faraday cages around sensitive apparatus; outsiders have to be disciplined to not break into the holy halls of science. Indeed, one function of the authority that scientists want to create and maintain for science is just the feeling of awe with the public, which shields the scientists from interference.

Scientists and technologists must be 'natural' sociologists, to create their restricted spaces. To achieve success, they must also be good at technical and social change engineering. They may not be able to articulate their skills in the discursive way that sociologists are addicted to, but they may well be more effective in practice. An interesting example is Pasteur's demonstration of the effectiveness of his anthrax vaccine for sheep. ${ }^{12}$ The first, and scientifically innovative step, was to move bits and pieces of the wider world ('samples', we now call them, after the fact) into a laboratory, where he could domesticate them-in this case, grow a culture of micro-organisms, and create a weakened version of the micro-organisms. The second, and socially innovative step, was that he attempted to change the way farmers treated their sheep, so as to create controlled conditions. He was able to do so for his demonstration experiment, to which he 
invited the Parisian opinion leaders. Having succeeded in this carefully staged demonstration, he could get his way in the 'Pasteurization' of France: a social reform if there was any.

When, and insofar as scientists can do away with audiences other than those of their immediate colleagues/competitors, the sociological dynamic essential to getting results from within a 'laboratory' or 'micro-cosmos' working and accepted outside of it, can be folded back onto itself. It is then limited to interactions within the relevant scientific community (or communities).

What has been called 'organized scepticism' of a scientific community, consisting of colleagues/ competitors only, can now be seen as a reduction of the sociological effort of the scientists to a minimal version: playing war games among themselves. Moreover, the internal struggles are becoming more public again. In his time, Pasteur was publishing by press conference, and this is what we now see happening again. And again, there are concerns about possible subversion of traditional mechanisms of quality control. My response is that there is no need to forbid such activities; they are part and parcel of search processes and attempts to do something with the results. The challenge is to devise, or let emerge, processes of quality control, for such presumably non-standard activities.

Local search processes have a natural science as well as a social science component. One or the other can be 'foregrounded' or emphasized, and scientists tend to publish only about the so-called natural science component. But both components are needed, and the notion that scientists, when publishing, should limit themselves to what was explicitly foregrounded in their research, is not absolute. Even if it will be the exception rather than the rule, the researcher can also publish about what was not foregrounded. Sir Peter Medawar, the Nobel-Prize-winning biologist, is one example; the title of his 1963 broadcast 'Is the Scientific Paper a Fraud?', on the difference between actual search practices and the written-up version is a classic reference in sociology of science. ${ }^{13}$ The scientist may publish suitable excerpts of his diary in a scholarly journal. While this happens occasionally (and can create controversy), ${ }^{14}$ a diary as such insufficiently adds to cosmopolitan knowledge. But a near equivalent is for scientists to draw on their accumulated experience and publish on the sociology of science; the British physicist John Ziman would be an outstanding example of this. ${ }^{15.16}$

\section{Scientists and society, and new kinds of story-telling}

The 'new combinations' I have discussed become visible when one focuses on the actions of the scientists, rather than the structure of the knowledge in a particular disciplinary framework. In the construction of the research setting and in the ongoing search processes, there is a 'natural' social component. This component can be made explicit, as has been done by reflective practitioners of science. There are other occasions in the work of scientists where the social component could be made explicit, and I will discuss two other areas of activity of scientists that are becoming increasingly important. One is scientific expertise, as it is delivered in advice, in testimony, and in reports that are an input in decision-making, especially about regulatory issues. (Indeed, in the USA, one now speaks of 'regulatory science'. ${ }^{17}$ ) The other area is the discussion of the impact of scientific research, not just in terms of promises being made, but also in relation to the question of social responsibility of scientists. In both cases, the focus on actions (search processes as well as other types of action) is important.

While advising is an activity with a tradition going back to Plato at the court of Dionysius, by now a scientific input into advice is often necessary to create legitimacy, that is, by linking the advice with a presently important source of authority and generality. (Although one should not exaggerate the authority of science: 'Ah, who believes scientists anyway', is a not uncommon feeling-see my earlier analysis of scientific expertise. ${ }^{18}$ ) Scientific findings now become transformed into expertise, rather than the truth-claims presented to scientific communities. This transformation requires additional considerations, e.g. of the context in which the expertise has to function, and also of the effect of the decisions if these were actually taken in line with the expert advice. In particular, the latter would require some social science input (or at least the expert's sensitivity to, and understanding of, social implications) to make the quality of the advice on this dimension comparable with the quality of the natural science expertise. 
Elsewhers, I have analyed how toxicological experts act in relation to the standard setting for chemicals wh as formaldehyde and dioxin, and have shown that they indeed take the social context into account in which the standards have to function. ${ }^{19}$ If they had accepted some of the toxicological evidence in the literature at face value, they would have come up with a standard that would have condemned the whole of Holland to be treated as a waste dump unfit for living. So they checked and double-checked, even made phone calls to one American laboratory to see whether there had been any replications. As there were not, they felt justified in neglecting this bit of eridence, and came up with a different mechanism for the toxicity, and a standard which required only limited cleaning up. Thus, 'organized scepticism' works here, but it is oriented by pragmatic criteria. One of the roxicologists has defended this 'pragmatic rationalism' explicitly, and against criticism of some of his utopian-rationalistic colleagues. Some of his arguments can also be found in the political science literature; some other arguments of his and of his opponents could have profited from being aware of the insights offered by social and political science research. ${ }^{20}$

The second area to be discussed is less articulated in the practices of scientists: it is the consideration of the social impacts of research, especially one's own research (or the research to which one's own work contributes). There have been claims that scientists should consider these, out of a sense of social reponsibility. In actual practice, it is much easier to emphasize the good things that might come out of one's research, if properly funded, than to do a balanced impact assessment. There is also the additional complication of the limited predictability of research outcomes, let alone their social impacts.

This is not a message of despair, though. Predictability is limited in every walk of life. One should be modest, i.e. aim at anticipation and foresight rather than prediction, and be practical, i.e. be prepared to do the limited things that are possible. The effects of scientific research occur through successive linkages in a chain, in which ever more actors and broader worlds are involved. Responsibility for the final effects thus diminishes. The linkages, however, are not random: the first steps, say in contacts with certain industrial firms or government agencies, make some further steps easier, and others more difficult. Exploitation of research results can be facilitated, as well as hindered, depending on the networks in whick the researchers move. To use a phrase from the economics of technical change: path dependencies occur. So while one may not be able to foresee eventual impacts, one can find out about the immediate and further network linkages, and how these will prejudice impacts.

Scientists have developed some ability to chart relevant networks when pushing the promise of their findings or findings-to-be. But the charts are unbalanced, asymmetric, and there are often surprises in what actually happens. The competence of social scientists in understanding and tracing networks might be invoked, by following their lead, or social scientists might be hired to do such a job. (Wim Smit's article, in this issue, discusses some of the social science insights on this point.) This could be a sensible division of labour; I myself am involved in such 'jobbing' in the areas of biotechnology and micro-optics. However, if scientists think they can send the social scientist, after the job is done, back to whatever reserve they think she/he belongs, then there is an imbalance, and in fact, a lack of recognition of the natural scientists of their own situation. At the very least, the social science component in their work should be recognized, whether it is taken up by professional social scientists or by themselves.

Implicit in this discussion is a notion of integration of natural science and social science, not in terms of problems requiring the competence of both, but because the actual practices of natural scientists contain a social component, and if one cares for quality in those components, one had better do something about it, rather than trust a (hoped-for) natural ability or (presumably adecaute) experience.

We should make a further step: search practices in the natural sciences also contain a humanities element. Think, in particular, of the story-telling of scientists. As Sir Peter Medawar phrased it: 'Scientists are building explanatory structures, telling stories which are scrupulously tested to see if they are stories about real life' (emphasis in the original). ${ }^{21}$ The story-telling about what they found can be in the specialized genre of a scientific article. (One can go further and include theories as stories, because they are 'useful fictions'; and causality, one of the backbones of classical and 
macroscopic physics, as the attribution of action to a source in a 'causal story'.)

If one looks at the broader range of products of natural scientists, one already sees stories about the promises they specify for proposed research when submitting research proposals, but also in other ways, in order to persuade some patron to fund them. Scientists are often 'natural' narrators, in addition to being 'natural' sociologists.

They are not always successful, though. And it would be important, anyway, to use whatever insights narrative analysis, cultural studies, and other relevant work in the humanities (and the increasingly mixed humanities and social science studies) have to offer. The sociology of science and technology also started out on this road; expectations (of probable outcomes, of useful directions to go, of heuristics to follow in the search process) are studied as a key element in the dynamics of scientific development, and are seen as sustained by story-telling and the take-up of such stories. ${ }^{22}$

One can combine this point with the earlier discussion and argue that if natural scientists are ever to become reflexive about their own research, about intended outcomes and unintended consequences, they must learn how to tell stories in which they themselves play a role (in contrast to the style of presentation with passive verbs, where no author is visible, and the laboratory world is taken to speak for itself). There is a hermeneutics of natural science, but it has been repressed. ${ }^{23}$ It is important to recreate it: not only for its own sake (being reflexive is better than not being reflexive), but also because it will make researchers more effective, as scientists and as citizens.

In such an endeavour, traditional philosophy and history, even when occasionally inspiring, are of less help-because they are not sufficiently knowledgeable about science-than the new area of science, technology and society studies. This scholarly community combines social science expertise with philosophy and history of science, and many of the active researchers have (also) some background in natural science. While the community has had a tradition of distanced, academic research (and another tradition of criticism of practices and ideologies of science), there is now-with the advantage of the insights won in the last three decades of work-a movement toward re-integration, and there are openings for a professional service role. ${ }^{24}$ As John Ziman phrased it, after noting the pressures on science in the 1990s: we should help science and technology to reinvent themselves. ${ }^{25}$

\section{A conglomerate of search practices}

With the discussion of the role of social science and humanities in the practice of natural science, I have described new combinations and suggested some further ones. I phrased my discussion in traditional categories, but it is now time to broaden the scope further and, in a sense, turn the tables.

If it is indeed fruitful to look at search practices, rather than global disciplinary distinctions, there is no reason to stop after considering the natural sciences. Social science and humanities also consist of search practices. That search practices in humanities often relate to linguistic, textual and visualization worlds does not make for a difference in principle in my argument. Having seen that, one can see all scientific and scholarly activities, not as some unified science, but as a conglomerate of search practices, and thus as a reservoir allowing a wide variety of new combinations, not necessarily limited to the ones starting from the activities and needs of natural scientists.

To prepare the way for a consideration of new combinations, actual and possible, and to open up thinking about science, let me propose that our traditional way of cutting up scientific and scholarly activities into science, social and behavioural science, and humanities (or some variant) is counterproductive, and that an alternative, much more interesting way is possible.

One should see the conglomerate of search processes as located in a triangle. Not alpha, versus beta, versus gamma, each of the three clustered at their own corner of the triangle. But a complex and entangled set of practices, which have components related to each of three poles, visualized as corners of a triangle: grammar, (hi)story, and nomology (law-oriented science/scholarship, with classical physics as the main example).

'Grammar' is a set of rules that can generate a variety of expressions; structuralism is a broad version of grammar, applicable to social and cultural phenomena, instead of just linguistic phenomena. Mathematics can usefully be classified as a variant of 'grammar' in this sense. There is an element of conventionalism, but also a relation to 
the phenomenal world (in the case of mathematics, this relation was traditionally with the physical world).

The second corner of the triangle, history and story, refers to collecting of events and phenomena, and telling about them. It is not limited to the humanities, as the term (and the practice) 'natural history' testifies. History and the Aristotelian tradition of natural science embrace the richness of phenomena. Statistics, in its original meaning of data collection for the state, is a stylized version of 'history'.

Until the beginning of the modern age, in the 16 th and 17 th centuries, 'grammar' and (natural) 'history', were the two ideal types of search processes available. With the emergence of experimental philosophy and the claim of a new role for mathematics, a third kind of search process evolved, the search for laws of nature. Historically, the notion of 'laws of nature' derives from God's laws, and was later reinforced by the emerging nation states and the political importance of ruling by law. ${ }^{26}$

It took time, and active proselytizing, to get the new approach accepted as legitimate. The Irish clergyman and philosopher Berkeley, thought the Newtonian theory a piece of grammatical pedantry, because it was not (natural) history, and thus must be grammar. As the science historian Stephen Mason put it:

'As in reading other books', Berkeley wrote in 1709, 'A wise man will choose to fix his thoughts on the sense and apply it to use, rather than lay them out in grammatical remarks on the language: so in perusing the volume of nature, it seems beneath the dignity of the mind to effect an exactness in reducing each particular phenomenon to general rules, or showing how it follows from them.' Newton's Principia, Berkeley thought, was one of the worst examples of this 'grammatical' study of nature.

By now, the style of experimental philosophy has become established. The austerity of its ideal of explanation is applauded, but criticisms remain. The revival of natural history in the environmental sciences sometimes leads to voicing of concerns similar to those of Bishop Berkeley. Whatever the value of these concerns, it is clear that there is a third ideal-type of search process, the third corner of the triangle. I will call this corner 'nomology', using a bit of jargon from the philosophy of science where Hempel's notion of 'deductivenomological explanation' has become widely used. ${ }^{28}$ 'Classical physics' could be another label, because this corner is about the regularized, law-like world that features so heavily in classical physics. By the turn of the century, a mathematicized and, to some extent, conventionalized version started to emerge, which undermined the security of classical physicists. (A novel has been written which brings out the identity problem of the classical physicists at the time. ${ }^{29}$ ) The new physics of the 20th century is located farther in the direction of 'grammar'.

Another 20th century development in physics, associated with Prigogine, is moving towards the second corner of the triangle, labelled history/ story, and linked with the tradition of natural history. Prigogine's criticism of classical physics is that it cannot grasp change, and thus neglects order evolving out of chaos. ${ }^{30}$ Life sciences, geology, all containing time/development as an essential component, have always lived with such evolutions, and have come to terms with them, balancing uneasily between the regularities of the nomological corner of the triangle, and the complexities of the (hi)story corner.

The (hi)story corner links up with 'grammar' again through structuralism and other intellectual movements. Social science sits uneasily within the triangle, partaking of regularities and (hi)story, but also linking up with structuralism/grammar when trying to identify deep structures behind social phenomena.

The triangular analysis of science and scholarship allows one to map the evolution of disciplines and the nature of new combinations. It is also a challenge, in the sense that one can imagine novel cross-sections through the conglomerate. These cross-sections can have different emphases, as can be illustrated with some 'new combinations' that have emerged already. Natural and technical sciences can be mixed, as in materials science, Cognitive sciences mix natural sciences, psychology, and parts of humanities. Cultural analysis is a new way of doing (hi)story, profiting from structuralism and ecological sciences.

Whatever substance the triangular analysis, as in Figure 1, may have, its value lies in the demonstration that the traditional distinction between (natural) sciences, social sciences, and 


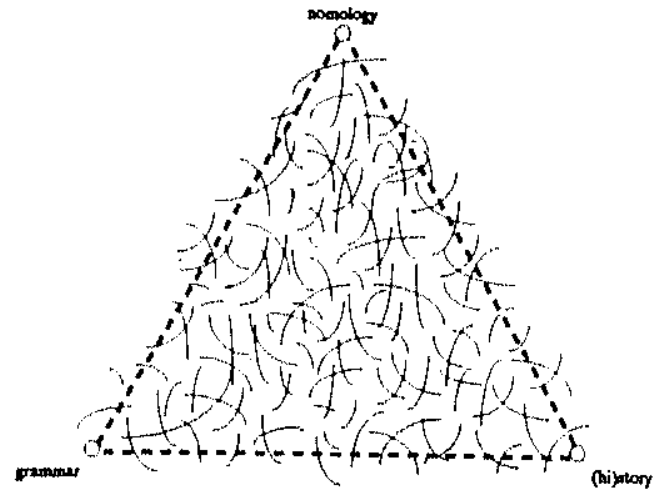

Figure 1. Science and scholarship as a conglomerate of search practices, structured by three poles.

humanities, is not necessarily the only possible one. It opens up a space for a fresh look at scientific and scholarly activity. One application was given in the previous section: highlighting the social science and humanities components of the cultivation of natural science, and showing that these deserve serious effort. When that is done, one could speak of 'dual' research, in the sense that a complementary, but 'backgrounded' activity is now also 'foregrounded'.

In the new space, new ideal-typical distinctions are possible, and fruitful. To mention one, Krohn and Weyer make a distinction between primary sciences, which help to (re)construct the world, and secondary sciences, which monitor, analyse, and assess what is happening in the world, partly because of the input of the primary sciences. Examples of secondary sciences are environmental sciences, modelling, risk analysis, technology assessment, strategic analysis. ${ }^{31}$ All of these examples mix traditional categories. In fact, the whole notion of a laboratory, as the protected space in which experimental philosophy can come into its own, is under pressure. ${ }^{32}$ An interesting additional example would be economics as a primary science, in the way it helps construct the life of the nation, and evaluation studies (of various kinds) as secondary science.

\section{In conclusion: what could an integrated science and technology policy be?}

When policies are problem-oriented, or focus on social missions, there is already de facto integration of traditional disciplines. But it could be done much better, when attors are conscious of what they do. Quality control should te developed, now based on hybrid communities. Such communities are present alreads, but they focus primarily on goal-setting and allocation of resources, rather than implementation and quality control.

In science-oriented policies, integrated ap. proaches have a hard time. One basic problem is that institutional atrangements are always slow to adapt to new developments. In science, they are geared to older, and possibly obsolete, disciplinary demarcations. So it is necessary to actively create room for experiment and innovation. One way to do so is to support the emergence of quality. control communities for integrated and/or hybrid approaches.

Policy makers should have the courage to be pro-active here, in the face of vested interests of the various disciplinary scientific communities. Policies cannot 'force' new combinations, but they can create circumstances and an infrastructure that helps, rather than hinders, their emergence. The argument in this article has been that the potential for new combinations exists alteady, but has to be stimulated. New perspectives, and new labels, when squarely located in ongoing search processes, will expedite this process.

\section{Acknowledgement}

This article is based on a paper presented to the Meeting 'An Integrated Approach to Science \& Technology Policy', organized by the Academia Europaea, Alvor (Portugal) 9-11 March 1994. Comments from participants, at the time, and in response to an earlier version, are gratefully acknowledged.

\section{REFERENCES}

1. C. Ginzburg (1979) Clues. Roots of a scientific paradigm. Theory and Society 7, 273-288.

2. A. Rip (1992). Science and technology as dancing partners. In P. Kroes and $\mathrm{M}$. Bakker (Eds) Technological Development and Science in the Industrial Age, pp. 231-270. Kluwer Academic, Dordrecht.

3. Th. S. Kuhn (1970) The Structure of Scientific Revolutions, second enlarged edition. University of Chicago Press, Chicago. 
4. Th. S. Kutm $(197)$ The Fontial Tensim. Selected

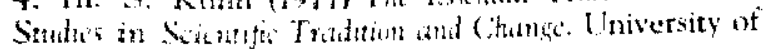
Chicigho Press, Chicato.

5. M. J. Mfulbay (1977) Sociolagy of the Scientitic Researeth Community. In l. Spieget-Rösing and D. J. de Solla Price (Eds) Sirne, Tohnology and Socey. A

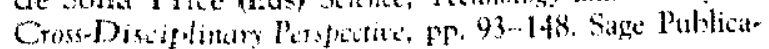
tions, Losdon and Beverly Hills.

6. A. L. Proter and F. A. Rossini (1984) Interdisciplinary research redefined: multi-skill, problem-tocused research in the STRAP framework. RED Management 14(2), 105-111.

7. F. A. Rossini and A. L. Porter (1985) Interdisciplinary research without disciplines, In B. W. Mar, W. T. Newell and B. O. Saxtery (Eds) Managing High Teihnology. An Interdisciflihary Persfectice, pp. 201-207. Elsevier Science Publishers, Amsterdam.

8. A. Rip. (1981) A cognitive approach to science policy. Research Policy 10, 29+-311.

9. A. Elzinga (1985) Research, bureaucracy and the drift of epistemic criteria. In B. Wittrock and A. Elzinga (Eds) The Unicersity Research System. The Public Policies of the Home of the Scientists, pp. 191-220. Almqvist \& Wiksell International, Stockholm.

10. A. Cambrosio, C.. Linoges and E. Hoffman (1992) Expertise as a network: a case study of the controversies over environmental release of genetically engineered organisms. In N. Stehr and R. V. Richardson (Eds) The Cultuse and Pouer of Knouledge. Inquiries into Contemporary Socictios, pp. 341-361. Walter de Gruyter, Berlin/New York.

11. A. Rip (1982) The development of restrictedness in the sciences. In N. Elias, H. Martins and R. D. Whitley (Eds) Scientific Establishments and Hierarchies, pp. 219238. Kluwer Academic, Dordrecht.

12. B. Latour (1983) Give me a laboratory and I will raise the world. In K. Knor -Cetina and M. J. Mulkay (Eds) Science Observed, pp. 141-170. Sage, London and Beverly Hills.

13. P. B. Medawar (1969) The Art of the Soluble. Penguin Books, Harmondsworth, p. 170.

14. F. W. Saris (1981) [Text of inaugural lecture, based on his diary as a physicist], De Gids.

15. J. Ziman (1968) Public Knowledge. The Social Dimension of Science. Cambridge University Press, Cambridge.

16. J. Ziman (1978) Reliable Knouledge. An Exploration of the Grounds for Belief in Science, Cambridge University Press, Cambridge.

17. S. Jasanoff (1990) The Fifth Branch. Science Advisers as Policy Makers. Harvard University Press, Cambridge, MA.

18. A. Rip (1985) Experts in public arenas. In H. Otway and M. Peltu (Eds) Regulating Industrial Risks. Sciente, Hazards and Public Protection, pp. 94-110. Butterworths, London.
19. A. Rip (1992) Experts and pragmatic rationality. In 19. A. Rip R. V. Ericson (Eds) The Culture and Power of Knouledge. Inquiries into Contemporary Societies, pp. $363-379$. Walter de Gruyter, Berlin/New York.

20. Y. Ezrahi (1980) Utopian and pragmatic rationalism: the political context of scientific advice. Minerva $18(1)$, $111-131$.

21. P. B. Medawar (1969) The Art of the Soluble. Penguin Books, Harmondsworth, p. 170.

22. H. van Lente (1993) Promising Technology. Eburon, Delft.

23. G. Markus (1987) Why is thete no hermeneutics of natural sciences? Some preliminary theses. Science in Context 1(1), 5-51.

24. A. Rip (1994) Science and technology studies and tonstructive technology assessment. EASST Newsletter, 13(3), 11-16; (Sept. 1994) Keynote speech, Conference of the European Association for the Study of Science and Technology, Budapest, 28-31 August 1994.

25. J. Ziman (1994) An ironic reflection. EASST Newsletter, 13(3), 17-18; (Sept. 1994).

26. E. Zilsel (1976) Die sozialen Ursprıng der neuzeitlichen Wissenschaft. Suhrkamp, Frankfurt/Main.

27. S. F. Mason (1962) A History of the Sciences, new revised edition. Collier Books, New York, p. 290.

28. C. G. Hempel (1966). Philosophy of Natural Science. Prentice-Hall, Englewood Cliffs, N.J.

29. R. McCormmach (1982) Night Thoughts of a Classical Physicist. Harvard University Press, Cambridge MA.

30. I. Prigogine and I. Stengers (1979) La Nowvelle Alliance. Métamorphose de la Science, éd. Gallimard, Paris.

31. W. Krohn and J. Weyer (1989) Die Gesellschaft als Labor. Risikotransformation und Risikokonstitution durch moderne Forschung. In J. Halfman, K. P. Japp (Hrsg.) Riskante Entscheidungen und Katastrophenpotentiale-Elemente einer soziologischen Risikoforschung. Westdeutscher Verlag, Opladen.

32. W. Krohn and J. Weyer (1994) Society as a laboratory: the social risk, of experimental research. Science and Public Policy 21(3), 173-183.

\section{Author's biography:}

Arie Rip is Professor of Philosophy of Science and Technology at Twente University, The Netherlands. His interests are in analysis of research policy and technology assessment. $\mathrm{He}$ is a past President of the International Society for the Social Studies in Science. His most recent (coedited) book is Managing Technology in SocietyThe Approach of Constructive Technology Assessment. 